\title{
Experiências do Pensamento Computacional no Ensino de Ciências e Matemática
}

\author{
Carine G. Webber*, Camila De Cesaro**, Deise Guder ${ }^{\star \star *}$, \\ Diego Flores $^{\star * * *}$, Joana Valim Becker ${ }^{* \star * * *}$
}

\section{Resumo}

O pensamento computacional e a inteligência artificial são temas emergentes na educação. Por compreenderem conceitos complexos e abrangentes, muitas estratégias estão sendo testadas e avaliadas, como formas de inseri-los efetivamente no ensino. Dentre os aspectos a considerar, tem-se a formação docente e seus desafios, tratados neste artigo. Nesta pesquisa, professores em formação conheceram o ambiente App Inventor e realizaram planejamentos de sequências didáticas combinando a programação de apps e os componentes curriculares de suas respectivas áreas. As etapas envolveram a programação e o planejamento das aulas, aqui brevemente expostos. Dentre as observações do estudo destaca-se que, apesar do desafio inicial da programação, todos os docentes envolvidos ficaram surpresos e motivados pelas potencialidades evidenciadas pela criação de aplicativos na escola.

Palavras-chave: Pensamento computacional, inteligência artificial, Ciências, Matemática, tecnologias, aplicativos, ensino, aprendizagem

* Doutora em Ciência da Computação pela Université Joseph Fourier, Grenoble, França. Professora do Programa de Pós-graduação em Ensino de Ciências e Matemática, Universidade de Caxias do Sul, RS, Brasil, email: cgwebber@ucs.br

* Mestranda do Programa de Pós-graduação em Ensino de Ciências e Matemática, Universidade de Caxias do Sul, RS, Brasil, email: ccesaro@ucs.br

.** Mestrandos do Programa de Pós-graduação em Ensino de Ciências e Matemática, Universidade de Caxias do Sul, RS, Brasil, email: dguder@ucs.br

**** Mestrandos do Programa de Pós-graduação em Ensino de Ciências e Matemática, Universidade de Caxias do Sul, RS, Brasil,email: dflores2@ucs.br

***** Mestrandos do Programa de Pós-graduação em Ensino de Ciências e Matemática, Universidade de Caxias do Sul, RS, Brasil, email: jvbecker@ucs.br 


\section{Introdução}

Diante da crise instaurada devido a pandemia do coronavírus, observou-se carências humanas e lacunas tecnológicas, que trouxeram imensos desafios mundiais. O cenário atual do ensino mudou a fim de garantir a continuação da educação no Brasil e no mundo. As instituições de ensino foram forçadas a buscar alternativas para que os processos de ensino e aprendizagem acontecessem fora do ambiente escolar presencial. Para isso, estudantes e professores foram obrigados a se adaptar, ajustar e até se reinventar por meio de aulas online, com a mediação de computadores, tablets e smartphones.

As tecnologias de informação e comunicação (TICs) compreendem sistemas, componentes e infraestrutura capazes de atender e solucionar diversos problemas da sociedade. Vive-se hoje em um mundo digital, sendo portanto natural projetar-se tecnologias para a mediação dos processos de ensino e aprendizagem (Brennan e Resnick, 2012; Demo, 2007; Perrenoud, 2000). Para além das funcionalidades ligadas à comunicação humana via TICs, tarefa indispensável em período de pandemia, todos os recursos computacionais, especialmente os aplicativos disponíveis para dispositivos móveis se tornaram necessários. A inteligência artificial, sub-área da ciência da computação, se revelou um recurso frequente para rastrear perfis, analisar dados e interagir nas formas da linguagem humana (Luger, 2013). Tantas mudanças repercutem no processo de ensino e aprendizagem, à medida que os meios físicos tradicionais, usados em sala de aula, se tornam inacessíveis.

Coube, portanto, aos professores o papel de repensar, planejar, estruturar suas práticas docentes a fim de lidar com os novos desafios da pandemia. Nessa perspectiva, a BNCC (2018, p. 1) propõe como competência geral a Cultura Digital. Neste mesmo texto ela é definida como um conjunto de habilidades que permitam

[...]compreender, utilizar e criar tecnologias digitais de informação e comunicação de forma crítica, significativa, reflexiva e ética nas diversas práticas sociais (incluindo as escolares) para se comunicar, acessar e disseminar informações, produzir conhecimentos, resolver problemas e exercer protagonismo e autoria na vida pessoal e coletiva.

De forma relevante, e destacada na própria BNCC, a Cultura Digital deve ser expandida para além do uso exploratório, ou mesmo aplicado, de softwares, simuladores, aplicativos, objetos de aprendizagem variados. Os recursos computacionais e 
tecnológicos devem ser trabalhados, inseridos e combinados para se integrarem aos componentes curriculares visando a construção de novos artefatos. Esta concepção fica evidente no seguinte detalhamento (BNCC, 2018, p. 2):

[...] é preciso lembrar que incorporar as tecnologias digitais na educação não se trata de utilizá-las somente como meio ou suporte para promover aprendizagens ou despertar o interesse dos alunos, mas sim de utilizá-las com os alunos para que construam conhecimentos com e sobre o uso dessas TDICs.

Uma forma de atender às premissas da Cultura Digital, pode ser pelo desenvolvimento do pensamento computacional. O pensamento computacional compreende um conjunto de habilidades relacionadas à forma com que os seres humanos podem usar os computadores para resolver problemas (Wing, 2006). Embora o conceito de pensamento computacional tenha sido abordado previamente por Papert (1980, p. 182), quando ele se referia às habilidades mobilizadas pelos estudantes durante o uso dos computadores e jogos, foi Wing (2006) quem o popularizou. Essa autora apresentou o conceito como um conjunto de habilidades básicas e necessárias que expandem a capacidade analítica dos estudantes, sendo assim importantes para todos, independentemente da área de estudo ou atuação. Diversos autores, recentemente, têm demonstrado a relevância da inserção das tecnologias em processos de ensino e aprendizagem em abordagens ativas e significativas (Borba e Penteado, 2019; Demo, 2007; Moran, Masetto e Behrens, 2015).

Apesar de tantos conceitos e diretrizes, sabe-se que nada pode se materializar na sala de aula sem o esforço do professor. Para Perrenoud (2000), o professor também precisa desenvolver competências, compreendendo sua capacidade em mobilizar-se cognitivamente para enfrentar as situações emergentes nos processos de ensino. Dentre as principais competências citadas pelo autor destaca-se a que trata de utilizar novas tecnologias, competência essa reforçada pelas demandas e desafios tecnológicos observados no período atual de pandemia e a competência geral da BNCC que trata da Cultura Digital. Partindo-se de tais observações, desenvolveu-se um projeto de formação docente a respeito dos princípios de programação para dispositivos móveis envolvendo professores mestrandos em formação. Em vista disso, o presente artigo apresenta a descrição das atividades planejadas pelos referidos professores voltadas ao ensino de Ciências e Matemática, integrando aspectos de programação, linguagens e mídias digitais. 


\section{Materiais e Método}

A presente seção descreve os elementos norteadores das atividades desenvolvidas com os professores, bem como os materiais empregados.

\section{Percurso experimental}

Para o planejamento das atividades foram buscados referenciais relativos à incorporação das tecnologias e da interação como eixos estruturantes dos processos de ensino e aprendizagem nas Ciências e na Matemática. Uma plataforma de programação visual em blocos para dispositivos móveis foi selecionada e apresentada aos professores. A programação, quando integrada a métodos de inteligência artificial, compõe um repertório de habilidades aplicáveis a todas as áreas do conhecimento, tornando os programadores aptos a resolverem problemas complexos.

Como recursos pedagógicos previstos inclui-se aplicativos gratuitos (MIT App Inventor ${ }^{1}$ ) e plugins públicos (reconhecimento de emoções nas expressões faciais). Em termos de aplicativos foram utilizadas plataformas de desenvolvimento de programas e de acesso a métodos de inteligência artificial. Cabe destacar que, por determinação da legislação educacional atual (BNCC), os temas relativos à tecnologia e à computação devem ser trabalhados de forma transversal em todas as áreas do conhecimento e componentes curriculares, desde a Educação Infantil até o Ensino Médio. Este elemento constitui base relevante para justificar e incentivar o uso e desenvolvimento das tecnologias em sala de aula.

Os professores participantes foram voluntários, estando matriculados na disciplina de Tópicos de Informática no Ensino. Para elaboração deste artigo selecionou-se quatro projetos desenvolvidos por professores nos anos de 2019 e 2020. Dada a extensão da formação, este artigo apresenta um recorte do desenvolvimento e do acompanhamento realizados. Para fins de procedimentos metodológicos tomou-se por base o modelo exposto por Massoni e Moreira (2017), cujas orientações guiaram os pesquisadores e contribuíram na tarefa da comunicação científica posterior. A pesquisa foi desenvolvida na universidade (anonimizado) e os artefatos desenvolvidos foram utilizados em sala de aula, supervisionada por um professor.

Durante o percurso das atividades, os professores envolvidos iniciaram se familiarizando e programando aplicativos simples no software App Inventor. Em 
um segundo momento, eles realizaram um planejamento didático completo, compreendendo diversas aulas e devendo culminar no desenvolvimento de um aplicativo executável para dispositivos móveis. Para o alcance do objetivo geral descrito nos planejamentos, e atendimento da BNCC, os projetos foram desenvolvidos com estudantes em diversos níveis escolares, a fim de construir uma base teórica e experimental para aprimorar, aperfeiçoar e desenvolver a pesquisa na área. A seguir, são expostos resumidamente os recursos tecnológicos empregados.

\section{Ambiente MIT App Inventor}

A plataforma MIT App Inventor consiste em uma ferramenta de programação baseada em blocos que permite que qualquer um, mesmo iniciantes, comecem a programar e construir aplicativos funcionais para dispositivos Android. $\mathrm{O}$ ambiente foi inicialmente desenvolvido pela Google e atualmente é mantido pelo Instituto de Tecnologia de Massachusetts (MIT). O App Inventor é uma ferramenta fácil de utilizar, até mesmo por quem não tem experiência em programação. $\mathrm{O}$ software é uma ferramenta de código aberto que visa tornar a programação e criação de aplicativos acessíveis para todos os públicos. De modo geral, ele é um ambiente de desenvolvimento de aplicativos para smartphones e tablets, o que constitui um atrativo para projetos escolares.

\section{Inteligência Artificial}

A Inteligência Artificial (IA) está inserida em nosso cotidiano, mas enquanto matéria desconhecida, provoca incertezas e insegurança. Contudo, a IA é uma área científica da Ciência da Computação, baseada em modelos matemáticos, biológicos, linguísticos, estatísticos e filosóficos. O termo nasceu na década de 50 para denominar uma área de conhecimento destinada a desenvolver métodos para aprimorar processos de resolução de problemas e a tomada de decisão humana (LUGER, 2013). Em termos práticos, a IA está inserida nas tecnologias por meio de programas de computador, escritos em linguagens de programação e processados por máquinas. Ou seja, o pensamento computacional também cobre os algoritmos de IA.

Recentemente programas que usam IA têm sido desenvolvidos, incorporados em sistemas complexos e questionados eticamente. A fim de preparar as gerações 
para lidar com sistemas cujos comportamentos são baseados em IA, diversos países têm adotado o seu ensino na escola. De acordo com Lee (2019), na China já existem muitas escolas experimentando a tecnologia da IA em sala de aula. Um exemplo é no reconhecimento de fala, para auxiliar na disciplina de inglês (que é obrigatório nas escolas chinesas). Neste caso, o sistema é treinado para avaliar a pronúncia dos alunos, ajudando na contação e no sotaque, sem a necessidade da presença de um nativo no idioma.

No contexto deste trabalho, a IA se insere na forma de componentes de programação (plugins) que podem ser adicionados na programação no ambiente App Inventor. Tais plugins, previamente desenvolvidos, permitem que funcionalidades como interação por voz e reconhecimento de faces e objetos, possam ser incorporadas em aplicativos desenvolvidos pelos professores e estudantes. Desta forma, os recursos inseridos podem tornar os aplicativos adaptáveis, interativos e sob alguns aspectos revelar comportamentos inteligentes, desde que programados. Considera-se possível inserir os conceitos de IA nos componentes curriculares, em produtos tecnológicos.

\section{Projetos aplicados ao Ensino de Ciências e Matemática}

Diversos aplicativos estão disponíveis nas lojas online para que estudantes e professores se apropriem e utilizem. Porém, é de suma importância que os estudantes tenham a oportunidade de criar seus próprios aplicativos, explorando conteúdos e designs e, desta forma, se apropriando dos componentes curriculares de diferentes maneiras. Para os docentes em formação, este tipo de atividade constitui um desafio pois implica em que eles desenvolvam competências em programação. No âmbito deste artigo foram desenvolvidos e analisados quatro planejamentos dos professores em formação, mestrandos em Ensino de Ciências e Matemática. As seções seguintes descrevem um breve relato das propostas individuais, ilustrando os temas e as perspectivas no uso transversal da programação com os componentes curriculares.

\section{Projeto I - Biologia}

O primeiro projeto considerou a utilização do ambiente MIT App Inventor para desenvolver o pensamento computacional aliado com a abordagem teórica dos conteúdos de Biologia. Desta forma, o público alvo previsto são estudantes do terceiro ano 
do ensino médio, de uma escola pública, com idades entre 17 e 18 anos, com pouca ou nenhuma experiência em programação. Os conteúdos abordados serão Primeira e Segunda Leis de Mendel. A proposta neste contexto é de que os estudantes criem uma calculadora que faça os cruzamentos destas leis, e que apresente exemplos clássicos da genética empregada.

O objetivo deste projeto é oportunizar aos estudantes a criação de um aplicativo para dispositivos móveis que agreguem a Primeira e a Segunda Lei de Mendel. Considerando que este é o primeiro aplicativo desenvolvido pela turma, um roteiro orientativo foi elaborado para ser disponibilizado. Os estudantes terão autonomia para explorar os recursos disponíveis na plataforma do App Inventor, mas devem programar componentes seguindo o roteiro descrito na figura 1. A tela de apresentação deve conter uma saudação inicial e uma orientação de como prosseguir na utilização do app. Ela deve disponibilizar dois botões que indicam as próximas telas: Primeira Lei de Mendel e Segunda Lei de Mendel. Cada tela irá conter suas respectivas funcionalidades. O ponto importante do app está na programação da calculadora genética, na qual o usuário poderá conhecer o resultado do cruzamento dos genes fornecidos. Para a programação da calculadora, os estudantes deverão ter clareza quanto aos conceitos e formas de cálculos envolvidos.

Segundo a avaliação do professor, o uso do App Inventor nas aulas de Biologia torna o conhecimento operacional, à medida que se materializa em um produto. Permite ainda a integração entre conceitos teóricos e a realidade tecnológica vivenciada fora da sala de aula. Após o desenvolvimento do aplicativo, as trocas e compartilhamento de aplicativos e aprendizagens entre estudantes é avaliado como um fator importante pelo professor. Espera-se que os estudantes se motivem com a possibilidade de criarem um aplicativo funcional, no qual seus colegas possam experimentar e sugerir modificações, e aliem seus conhecimentos da disciplina com a criatividade e construção de artefatos tecnológicos. 
Figura 1: Mapa do roteiro das telas do App Inventor

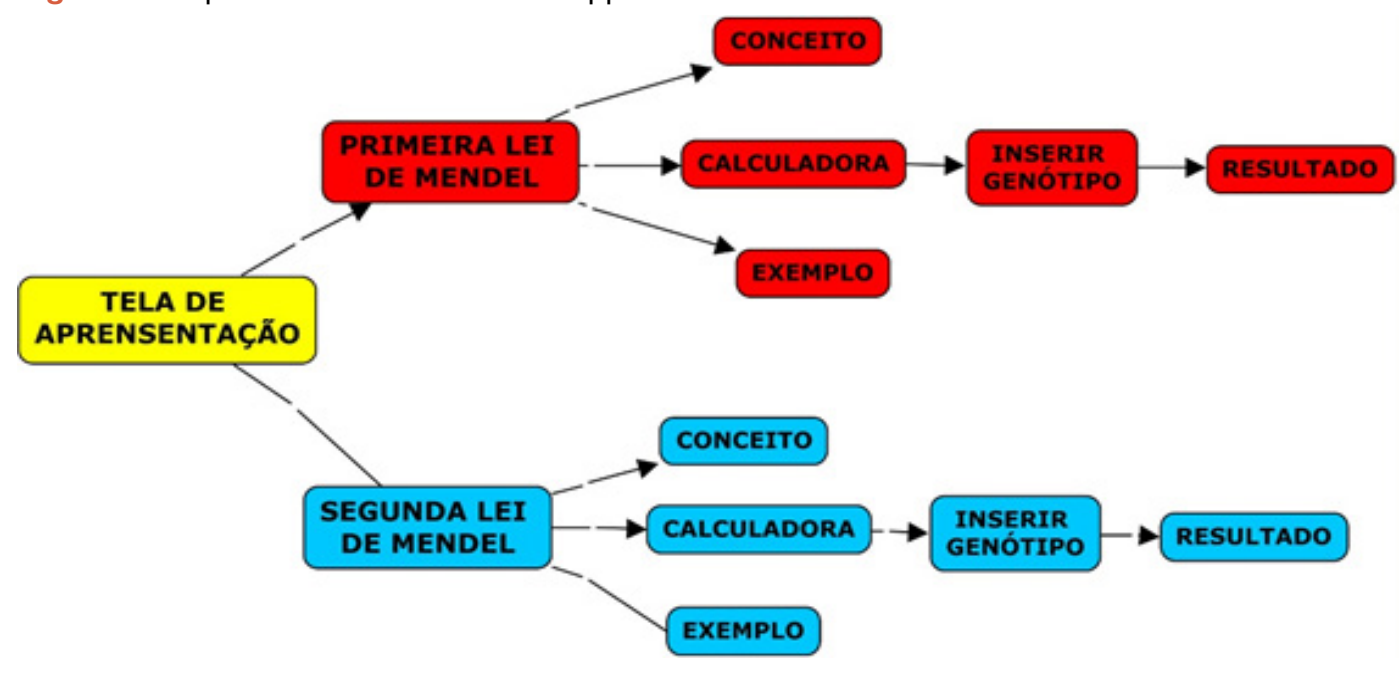

Projeto I| - Inteligência Artificial

O segundo projeto investigou a inserção da inteligência artificial em um produto simples a ser desenvolvido no App Inventor. Dentre as habilidades do pensamento computacional, a inteligência artificial se ocupa de tarefas variadas, dentre as quais uma que trata do reconhecimento de padrões. Reconhecer padrões é uma tarefa naturalmente humana, mas que as máquinas estão aprendendo a realizar com sucesso. Um exemplo é o reconhecimento da face e de emoções nas faces.

Sendo assim, o objetivo desse projeto é proporcionar aos estudantes aprender a criar um aplicativo que fotografe imagens de faces e, na medida que as imagens são capturadas e armazenadas, elas possam ser classificadas em termos das emoções humanas reconhecidas. Para esta tarefa, utiliza-se um componente denominado Personal Image Classifier (figura 2). Ele permite a classificação automática de imagens a partir de um modelo modelo de classificação de imagens. O modelo é criado a partir de fotos de faces, coletadas, treinadas e armazenadas em uma banco de dados local. 
Figura 2: Ambiente web da extensão Personal Image Classifier (carregamento das imagens (à esquerda) e teste das expressões faciais (à direita)
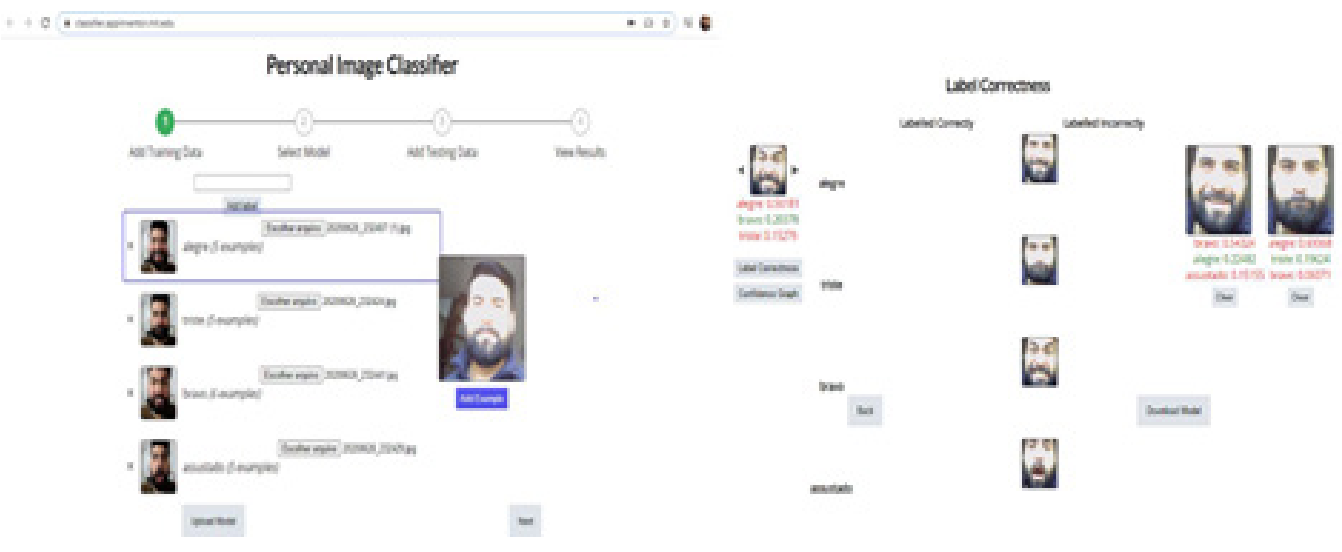

Neste projeto são exploradas as habilidades do pensamento computacional no que diz respeito ao reconhecimento de padrões e o desenvolvimento de algoritmos. Os estudantes necessitam de noções prévias de programação e sobre reconhecimento de padrões. Os recursos do App Inventor permitem facilmente o desenvolvimento de um protótipo, que permite aos estudantes registrar suas próprias fotos e testar se a expressão corresponde com a classificação dada pelo aplicativo. Caso isso não ocorra, os estudantes podem intervir e auxiliar o algoritmo no treino indicando qual seria a emoção correta expressa na face. A figura 2 ilustra imagens da face do professor e as classificações obtidas. Por meio da construção do aplicativo, os estudantes podem se aproximar das bibliotecas de inteligência artificial, aproximando-se desta área de conhecimento por meio da elaboração de produtos simples.

\section{Projeto III - Matemática}

O terceiro projeto propôs a construção de aplicativos sobre o cálculo de perímetro e área, por estudantes de $7^{\circ}$ ano do Ensino Fundamental, que estejam tendo um primeiro contato com o ambiente de programação MIT App Inventor. Já existem disponíveis no mercado, gratuitamente, vários aplicativos que possibilitam o cálculo de perímetros e áreas. Porém, todos os aplicativos localizados em uma pesquisa preliminar realizada pela professora apresentam características que não são as ideais para o que se pretende trabalhar com os estudantes do $7^{\circ}$ ano (perímetro e 
área de triângulos e quadriláteros). Isto ocorre pois alguns são direcionados para a engenharia e construção civil ou para a topografia. Outros ainda apresentam o cálculo para muitas figuras diferentes (não apenas triângulos e quadriláteros), incluindo também cálculo de volumes e várias funções que são direcionadas a anos posteriores ( $8^{\circ}$ ou $9^{\circ}$ ano do Ensino Fundamental), além do Ensino Médio ou Superior. Diversos aplicativos não estão na Língua Portuguesa. Sendo assim, propõe-se um aplicativo simples, com menos informações, apenas abordando os assuntos trabalhados com os estudantes do $7^{\circ}$ ano. A figura 3 ilustra uma tela do aplicativo, onde são apresentadas as figuras geométricas na forma de objetos clicáveis na tela.

A fim de prever o contexto de uso do aplicativo, foi elaborada uma sequência didática. Nela, inicialmente devem ser trabalhados os conceitos de perímetro e área e realizada a construção das fórmulas das áreas do triângulo e dos quadriláteros, através de atividades práticas, como por exemplo, com o uso de papel quadriculado e por meio de decomposições e composições de figuras. Posteriormente, prevê-se a apresentação de um aplicativo construído pela professora, como modelo, para os estudantes interagirem. Em seguida, a professora apresenta o software App Inventor, mostrando suas principais características e funções, demonstrando alguns passos iniciais para o desenvolvimento de um aplicativo, usando o modelo apresentado para os estudantes (figura 3).

Seguindo no planejamento, deve-se solicitar que os estudantes construam um aplicativo que realize os cálculos de perímetro e área estudados, usando o App Inventor. Cada estudante deve explorar o ambiente de programação, testando funcionalidades, fazendo modificações e depurando, em um processo iterativo até obter o produto desejado. Por fim, os aplicativos construídos podem ser disponibilizados para os colegas da turma, que irão usá-los e testá-los, realizando atividades de aula (como exercícios propostos pela professora). 
Figura 3: Tela exemplo do aplicativo modelo construído pela professora (à esquerda) e ambiente MIT App Inventor com a tela inicial do aplicativo (à direita)
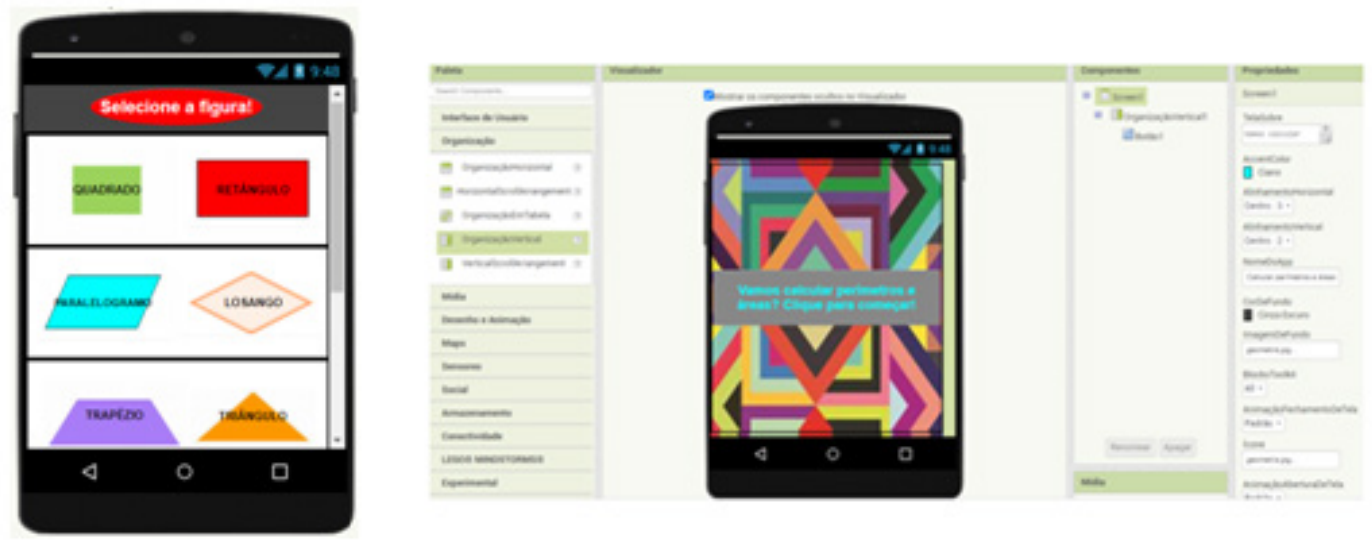

O uso do aplicativo, nesse contexto, servirá para sistematizar os objetos de conhecimento estudados (perímetro e área de triângulos e quadriláteros), além de possibilitar aos estudantes conhecerem a linguagem de programação, promovendo a integração das tecnologias digitais em sala de aula.

\section{Projeto IV - Matemática}

O quarto projeto foi desenvolvido e aplicado em turmas do $6^{\mathrm{o}}$ ano do Ensino Fundamental no componente curricular de matemática. O objetivo da atividade é potencializar o conteúdo de matemática utilizando recursos tecnológicos, estimulando a interação entre os alunos e tornando-os protagonistas do aprender, desenvolvendo habilidades de programação e de matemática.

Conforme a BNCC (2018), espera-se que sejam desenvolvidas por meio desta atividade as habilidades assim descritas: resolver e elaborar problemas que envolvam as grandezas comprimento, massa, tempo, sem uso de fórmulas, inseridos, sempre que possível, em contextos oriundos de situações reais e/ou relacionadas às outras áreas do conhecimento. Dentre as competências específicas de matemática para o ensino fundamental presentes na BNCC, destaca-se para esta atividade a de desenvolver o raciocínio lógico, o espírito de investigação e a capacidade de produzir argumentos convincentes, recorrendo aos conhecimentos matemáticos para compreender e atuar no mundo. 
Após a etapa de planejamento, o projeto foi aplicado no laboratório de informática da escola, onde os alunos trabalharam em duplas e foram desafiados a construírem um aplicativo sobre unidades de medida: comprimento, superfície e tempo. Eles também acrescentaram informações sobre área e perímetro. Foram utilizadas 6 telas para a construção do aplicativo. A tela inicial continha os botões "Comprimento", "Perímetro", "Superfície”, “Área” e "Tempo", que ao serem clicados, abrirão as cinco respectivas partes do aplicativo. Os botões envolvendo as grandezas apresentavam uma breve explicação de cada uma juntamente com a tabela de conversão de medidas.

A professora utilizou a tela inicial como modelo para explicar e ilustrar as funcionalidades do aplicativo. Em seguida, cada dupla elaborou o restante das telas. O aplicativo desenvolvido favoreceu o processo de aprendizagem sobre Grandezas e Medidas, sendo uma ferramenta que pode ser utilizada para consulta durante $o$ Ensino Fundamental e Ensino Médio na área da Matemática e das Ciências da Natureza. A figura 4 ilustra imagens da tela inicial do aplicativo e a sua programação.

Figura 4: Registro do desenvolvimento do aplicativo pelos estudantes
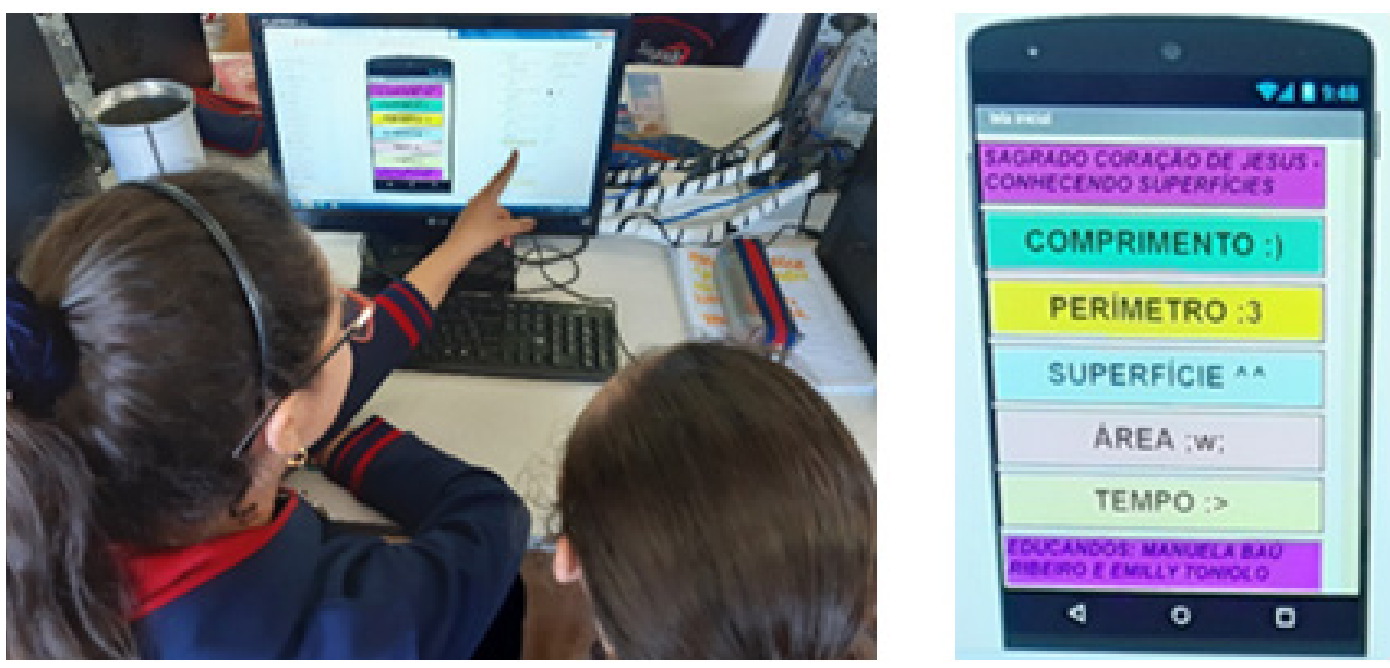

\section{Considerações Finais}

O pensamento computacional compreende um conjunto de habilidades relacionadas à forma com que os seres humanos podem usar os computadores para resolver problemas. No ensino, já tem sido amplamente demonstrado pela literatura e pelas 
escolas, que a programação pode trazer benefícios ao processo de aprendizagem pois favorece o desenvolvimento de habilidades analíticas e metacognitivas, além da interação social e criatividade. Por meio deste projeto, professores tiveram seu primeiro contato com um ambiente de programação em blocos, visual e para dispositivos móveis. Os resultados observados evidenciam a capacidade docente em elaborar, conceber e planejar atividades educacionais, interdisciplinares, integradas aos componentes curriculares de suas áreas.

Do ponto de vista dos docentes que participaram das atividades aqui descritas, o aprendizado de programação é um grande desafio. Contudo, ele não impediu os professores de aprenderem a programar e assim planejar sequências didáticas potencialmente válidas. De forma convergente, os professores reconheceram o potencial de uma linguagem de programação para desenvolvimento de habilidades importantes e algumas muito complexas de serem desenvolvidas se tomados os componentes curriculares isoladamente. Dentre elas, os professores destacaram as seguintes:

a) a capacidade de construir um app por meio da combinação de instruções simples, materializando e atribuindo novo significado ao conhecimento;

b) a capacidade de ordenar e estruturar o pensamento, favorecendo a construção do raciocínio lógico; e,

c) desenvolver aspectos cognitivos e metacognitivos visados, a partir da engenharia reversa da programação e das situações de tentativa e erro/acerto comuns na área.

Para finalizar, conclui-se que a utilização do ambiente MIT App Inventor foi benéfica nesta formação. Os professores participantes reconheceram que ele apresenta vantagens que favorecem a construção de experiências computacionais ao longo dos processos de ensino e aprendizagem, tão visadas quando se trata de conteúdos abstratos, complexos e teóricos das Ciências e da Matemática. Assim como, as Ciências avançam graças aos recursos tecnológicos, também o ensino nas Ciências e na Matemática precisa se valer destes mesmos recursos para que o conhecimento e a sociedade prossigam. 


\section{Computational Thinking Experience applied to Science and Math Teaching}

\section{Abstract}

Computational thinking and artificial intelligence are emerging topics in education. Once they comprehend complex concepts, there is a need to test and evaluate strategies as ways to effectively integrate them into teaching activities. Among the aspects to be considered, teaching formation is a challenging issue. In this paper, we present an experiment involving teachers, as novice programmers, exploring the MIT App Inventor environment, and planning teaching sequences combined to curriculum components from their respective areas. The experiment steps started with basic programming and then planning classes, which are briefly exposed here. Among the findings of this work, it is noteworthy that, despite the initial programming challenge, all the teachers involved were surprised and motivated by the potential of creating apps.

Keywords: Computational thinking, artificial intelligence, Science, Math, technology, applications, teaching, learning.

\section{Nota}

1 Disponível em: https://appinventor.mit.edu/

\section{Referências}

BRASIL. Base Nacional Comum Curricular. Brasília, DF: Ministério da Educação. 2018.

BRENNAN, K.; RESNICK, M. New frameworks for studying and assessing the development of computational thinking. 2012. In: Proceedings of the 2012 annual meeting of the American Educational Research Association, Vancouver, Canada, 2012.

BORBA, Marcelo de Carvalho; PENTEADO, Miriam Godoy. Informática e Educação Matemática. 6. ed. Belo Horizonte: Autêntica Editora, 2019.

DEMO, Pedro. Educação e Qualidade. 11. ed. Campinas, SP: Papirus, 2007.

LEE, K. F. A inteligência Artificial - Como os robôs estão mudando o mundo, a forma como amamos, nos comunicamos e vivemos; tradução Marcelo Barbão. Rio de Janeiro: Globo Livros, 2019.

LUGER, George F. Inteligência artificial. Tradução Daniel Vieira. São Paulo: Pearson Education do Brasil, 2013.

MASSONI, N. T.; Moreira, M. A. Pesquisa Qualitativa em educação em ciências: projetos, entrevistas, questionários, teoria fundamentada, redação científica. São Paulo: Editora Livraria da Física, 2017.

MIT App Inventor. Disponível em: https://appinventor.mit.edu. Acesso em: 2 fev. 2021. 
MORAN, José Manuel; MASETTO, Marcos Tarciso; BEHRENS, Marilda Aparecida. Novas tecnologias e mediação pedagógica. Campinas, SP: Papirus, 2015.

PAPERT, Seymour. A máquina das crianças: repensando a escola na era da informática. Porto Alegre: Artmed, 2008.

PERRENOUD, Philippe. Dez Novas Competências para Ensinar. Porto Alegre: Artmed, 2000.

WING, Jeannette Marie. Computational thinking. Communications of the ACM, v. 49, n. 3, p. 33-35. 2006. 